\title{
Performance assessment of solar air heater duct roughened with perforated-winglet vortex generators
}

\author{
Narin Koolnapadol ${ }^{\mathrm{a}}$, Pongjet Promvonge ${ }^{\mathrm{b}}$, Sompol Skullong ${ }^{\mathrm{c}, *}$ \\ ${ }^{a}$ Department of Automotive Mechanical Engineering, Faculty of Industrial Technology Rajabhat Rajanagarindra University, \\ Chachoengsao, Thailand \\ ${ }^{b}$ Department of Mechanical Engineering, Faculty of Engineering, King Mongkut's Institute of Technology Ladkrabang, Bangkok, \\ Thailand \\ ${ }^{c}$ Department of Mechanical Engineering, Faculty of Engineering at Sriracha, Kasetsart University Sriracha Campus, 199 M.6, \\ Sukhumvit Rd., Sriracha, Chonburi, Thailand
}

\begin{abstract}
An experimental study has been conducted to investigate heat transfer, friction loss and thermal performance characteristics of turbulent flow in a solar air heater channel artificially roughened on one side (absorber plate) with multiple perforated-winglet vortex generator (PWVG). Air as the working fluid enters the test duct having a uniform surface heat-flux with Reynolds number (Re) ranging from 5200 to 24,000 in the present work. Effects of four different punched hole/pore diameters of winglet $(d=2 \mathrm{~mm}, 4 \mathrm{~mm}, 6 \mathrm{~mm}$ and $8 \mathrm{~mm})$ at a single relative winglet height $\left(\mathrm{R}_{\mathrm{B}}=b / H=0.6\right)$, relative winglet pitch $\left(\mathrm{R}_{\mathrm{P}}=P / H=3\right)$ and attack angle $\left(\beta=60^{\circ}\right)$ on thermal characteristics are examined. The experimental results show that the PWVG provides the drastic increase in Nusselt number $(\mathrm{Nu})$ and friction factor $(f)$ values over the flat/smooth channel. In addition, substantial increases in $\mathrm{Nu}$ and $f$ values are found for the rise in hole sizes. The maximum Thermal Enhancement Factor (TEF) is found for the pore diameter of $2 \mathrm{~mm}$ at lower Reynolds number. The present results are also compared with the results from the typical or solid winglet, TWVG (non-punched hole of winglet).
\end{abstract}

Keywords: Absorber plate; V-baffle; vortex generator; solar air heater; thermal performance

\section{Introduction}

Air heating system using solar energy (Solar Air Heater, SAH) is one of the effective methods for harnessing solar energy on a large scale for thermal applications. SAH has been widely used in engineering and agriculture industry applications such as heat exchanger, crop drying, space heating and so on. In general, thermal performance of conventional absorber plate of SAH is significantly low because of the development of thermal boundary layer near the absorber plate leading to low convective heat transfer coefficient. To obtain higher heat transfer coefficient between the absorber plate and airflow, the boundary layer near the absorber plate must be destroyed and this can be achieved by using the artificial roughness in the form of fin/rib/baffle/wing/winglet (called "vortex generator", VG) on the underside of the absorber plate. The application of artificial roughness in the form of fin/rib/baffle/wing/winglet on the heated surface has been recommended to enhance the rate of heat transfer by several investigators.

For using the ribs/baffles in duct/channel heat exchanger and SAH, Taslim et al. [1] examined the heat transfer behaviors in a ribbed square channel with three relative rib-heights $(e / H=0.083,0.125$ and 0.167$)$ and a fixed rib-pitch ratio, $P / e=10$ using a liquid crystal technique. They reported that the average Nusselt number increased with the rise in $e / H$ ratio and the optimum $e / H$ was found to lie between 0.083 and 0.125. Varun et al. [2] and Hans et al. [3] carried out the reviews of roughness surface geometry in

\footnotetext{
* Manuscript received October 23, 2016; revised January 26, 2017.

Corresponding author; E-mail address: sfengsps@src.ku.ac.th.

doi: $10.12720 /$ sgce.6.1.31-39
} 
solar air heaters (SAHs). They reported on SAHs fitted with different roughness geometries and provided details of the concept of artificial roughness, effects of various roughness parameters on the flow pattern and also briefly discussed the roughness geometries used in heat exchangers. The effect of rib arrangements placed at $60^{\circ}$ with $e / H=0.09$ and the relative rib pitch of 1.0 on heat transfer in a channel with uniformly heating the four walls was experimentally investigated by Mochizuki et al. [4]. Lee et al. [5] studied experimentally the heat/mass transfer in rectangular channels with two different V-shaped ribs: continuous $60^{\circ} \mathrm{V}$-shaped and multiple (staggered) $45^{\circ} \mathrm{V}$-shaped ribs. Tamna et al. [6] examined experimentally and numerically the performance of multiple V-baffle vortex generators (BVG) in a SAH. They found that the single BVG with $\mathrm{PR}=0.5$ gave the best heat transfer performance and the numerical results were in good agreement with experimental results.

To date, most wing/winglet type vortex generators (WVGs) have been widely employed to improve the thermal performance of heat exchanger and SAH systems due to its merit of very low pressure loss and ease of manufacture and installation in comparison with others. Skullong et al. [7] reported the forced convection and pressure loss in a SAH channel with combined wavy-groove and perforated-delta wing vortex generator (WVG). They suggested that the use of WVG on the absorber plate yielded the maximum Nusselt number around 6.18 times above the smooth channel. Promvonge et al. [8] investigated fluid flow and heat transfer behaviors of a SAH channel with combined rib and delta-winglet (DW). They found that the $60^{\circ} \mathrm{DW}$ pointing upstream (PU-DW) yields the highest increase in both Nusselt number and friction factor while the lowest attack angle of the DW pointing downstream (PDDW) provides the best thermal performance. Influence of delta winglet vortex generator on heat transfer and friction behaviors in a SAH channel was studied by Skullong and Promvonge [9] and the significant increase in heat transfer rate and friction factor over the smooth channel was noted.

The literature review cited above indicates that the vortex generator are among the most effective and practical methods for augmenting heat transfer in ducts/channels. In duct/channel SAH systems, the investigation on using the rectangular-winglet type vortex generator with punched hole (called "perforated-winglet vortex generator", PWVG) has rarely been reported. Thus, the main aim of the present work is to investigate the thermal and flow friction characteristics in a duct SAH equipped with PWVG. The effect of PWVG placed only on the absorber plate with four different punched hole/pore diameters of winglet $(d=2 \mathrm{~mm}, 4 \mathrm{~mm}, 6 \mathrm{~mm}$ and $8 \mathrm{~mm})$ at a single relative winglet height $\left(\mathrm{R}_{\mathrm{B}}=b / H=0.6\right)$, relative winglet pitch $\left(\mathrm{R}_{\mathrm{P}}=P / H=3\right)$ and attack angle $\left(\beta=60^{\circ}\right)$ on fluid flow and thermal characteristics is examined in this work.

\section{Experimental Facility}

Wherever Times is specified, Times Roman or Times New Roman may be used. If neither is available on your word processor, please use the font closest in appearance to Times. Avoid using bit-mapped fonts if possible. True-Type 1 or Open Type fonts are preferred. Please embed symbol fonts, as well, for math, etc.

\subsection{Experimental setup}

The experiments were conducted in an open loop experimental facility as shown in Fig. 1. In the experiment, cold air at ambient condition was passed through the uniform heat flux duct for Reynolds number in a range of 5200-24,000. The tested duct was heated by an electrical heater plate attached on the upper wall (absorber plate) to provide a maximum uniform wall heat flux of about $2000 \mathrm{~W} / \mathrm{m}^{2}$ maintained using a variac transformer. The outer surface of the tested duct was well insulated to minimize convective heat loss to the surrounding. A SAH duct including a calm section $(2 \mathrm{~m})$, test section $(0.42 \mathrm{~m})$ and exit $(0.3 \mathrm{~m})$ was employed after the settling tank. The aluminum tested duct (absorber plate) having duct height $(H)$ of $30 \mathrm{~mm}$ with $300 \mathrm{~mm}$ width $(W)$ and $6 \mathrm{~mm}$ thickness $(t)$. The inlet and outlet temperatures of the bulk air were measured at certain points with a fluke $2680 \mathrm{~A}$ data acquisition system in conjunction with two RTD-type thermocouples. Twelve chromel-constantan (K-Type thermocouples) 
were tapped on the upper wall of the test duct to measure the temperature variation along the absorber plate to obtain the mean wall temperature. Also, the pressure drop across the test duct fitted with PWVG was measured with a digital manometer. More details on the experimental setup, method and uncertainty analysis are similar as reported in an earlier paper [7].

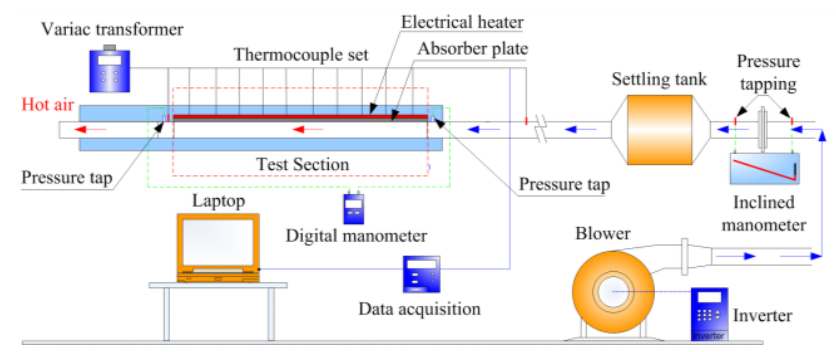

Fig. 1. Schematic diagram of experimental setup for SAH.

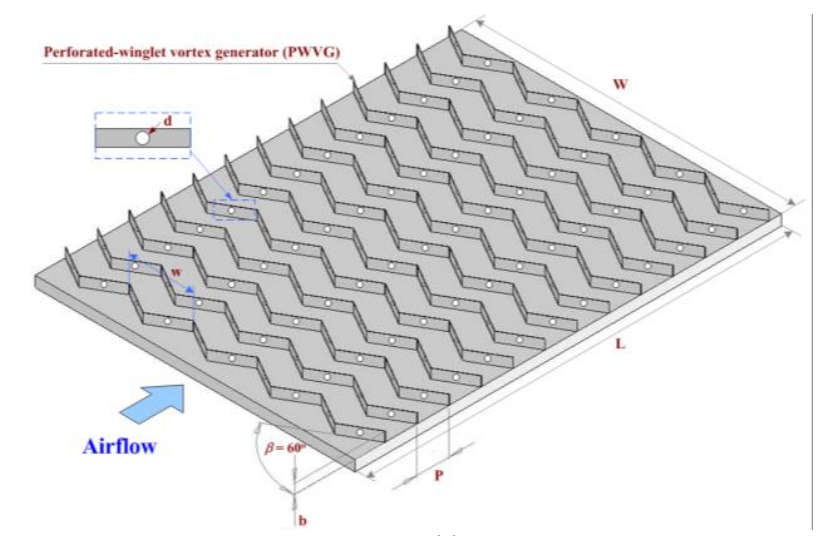

(a)

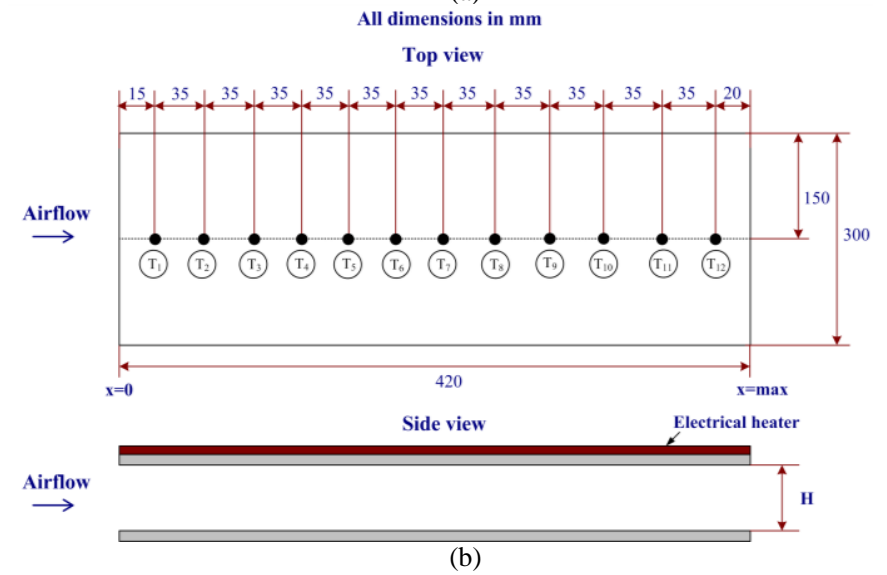

Fig. 2. (a) Test section with $60^{\circ} \mathrm{PWVG}$ and (b) position of thermocouples on the absorber plate.

\subsection{Winglet artificial roughness}

The PWVG used in the present study is shown in Fig. 2a. Each rectangular-winglet made of a $0.5 \mathrm{~mm}$ thick aluminum strip $(\delta)$ was placed on the absorber plate (upper wall) with the angle of attack $(\beta)$ of $60^{\circ}$ relative to the main flow direction and the width (w) of each winglet set to two times of channel height $(=2 \mathrm{H}$ or $60 \mathrm{~mm})$. The perforations of the artificial roughness were prepared for four different punched hole/pore diameters of $2 \mathrm{~mm}, 4 \mathrm{~mm}, 6 \mathrm{~mm}$ and $8 \mathrm{~mm}$ on the winglets while the relative winglet height $\left(R_{B}\right)$ and relative winglet pitch $\left(R_{P}\right)$ were kept constant at 0.6 and 3 , respectively. The duct geometry and 
position of the thermocouples on the absorber plate is depicted in Fig. 2b. Different configurations of PWVG roughness and test conditions used in experimental investigation are tabulated in Table 1.

Table 1. Different configurations of PWVG roughness and test conditions used in experimental investigation

\begin{tabular}{|l|l|}
\hline Working fluid & Air \\
\hline Reynolds number & $5200-24,000$ \\
\hline Absorber plate width, $W$ & $300 \mathrm{~mm}$ \\
\hline Absorber plate length, $L$ & $420 \mathrm{~mm}$ \\
\hline Relative winglet height $\mathrm{R}_{\mathrm{B}}$ & $0.6(18 \mathrm{~mm})$ \\
\hline Relative winglet pitch, $\mathrm{R}_{\mathrm{P}}$ & 3 \\
\hline Winglet attack angle, $\beta$ & $60^{\circ}$ \\
\hline Punched hole diameter on winglet, $d$ & $2,4,6,8 \mathrm{~mm}$ \\
\hline
\end{tabular}

\section{Data Reduction}

The purpose of the current work is to determine the heat transfer coefficient between the absorber plate and air in a SAH duct fitted with PWVG. The parameters of interest are Reynolds number (Re) and punched hole/pore diameter $(d)$. The Re is given by

$$
R e=U D / v
$$

The friction factor $(f)$ calculated from pressure drop is written as

$$
f=\frac{2}{(L / D)} \frac{\Delta P}{\rho U^{2}}
$$

in which $U$ is mean air velocity in the test tube.

In the experiment, air flowed through the SAH under a uniform wall heat-flux. The steady state of the heat transfer rate is assumed to be equal to the heat loss from the test section which can be expressed as:

$$
Q_{\text {air }}=Q_{\text {conv }}
$$

where

$$
Q_{\text {air }}=\dot{m} C_{\mathrm{p}, \text { air }}\left(T_{\text {out }}-T_{\text {in }}\right)
$$

The convection heat transfer from the test section can be written by

$$
Q_{\text {conv }}=h A\left(\tilde{T}_{\mathrm{a}}-T_{\mathrm{b}}\right)
$$

in which

$$
T_{\mathrm{b}}=\left(T_{\text {out }}+T_{\text {in }}\right) / 2
$$

and

$$
\tilde{T}_{\mathrm{a}}=\sum T_{\mathrm{a}} / 12
$$

where $T_{\mathrm{a}}$ is local absorber plate temperature located equally along the outer surface of the test duct (see Fig. 2b). The average heat transfer coefficient $(h)$ and Nusselt number $(\mathrm{Nu})$ are estimated as follows:

$$
h=\dot{m} C_{\mathrm{p}, \text { air }}\left(T_{\text {out }}-T_{\text {in }}\right) / A\left(\widetilde{T}_{\mathrm{a}}-T_{\mathrm{b}}\right)
$$


The heat transfer is calculated from the average $\mathrm{Nu}$ which can be obtained by

$$
\mathrm{Nu}=\frac{h D}{k}
$$

All of thermo-physical properties of air are determined at the overall bulk air temperature $\left(T_{\mathrm{b}}\right)$ from Eq. (6).

To assess the practical use, thermal performance of the artificial roughness is evaluated relatively to the smooth duct at an identical pumping power in the form of thermal enhancement factor (TEF) which can be expressed by

$$
\mathrm{TEF}=\left(\frac{\mathrm{Nu}}{\mathrm{Nu}_{0}}\right)\left(\frac{f}{f_{0}}\right)^{-1 / 3}
$$

where $h_{0}$ and $h$ stand for heat transfer coefficients of smooth duct and artificial roughness of SAH, respectively.

\section{Results and Discussion}

\subsection{Validation test of smooth duct}

To evaluate the reliability of the present experimental facility, the experimental results are validated by comparing the results from smooth duct with the Dittus-Bolter and Blasius equations [10] for Nusselt number $(\mathrm{Nu})$ and friction factor $(f)$ as shown in Figs. 3 and 4, respectively.

Dittus-Boelter equation,

$$
\mathrm{Nu}=0.023 \operatorname{Re}^{0.8} \operatorname{Pr}^{0.4}
$$

Blasius equation,

$$
f=0.316 \operatorname{Re}^{-0.25}
$$

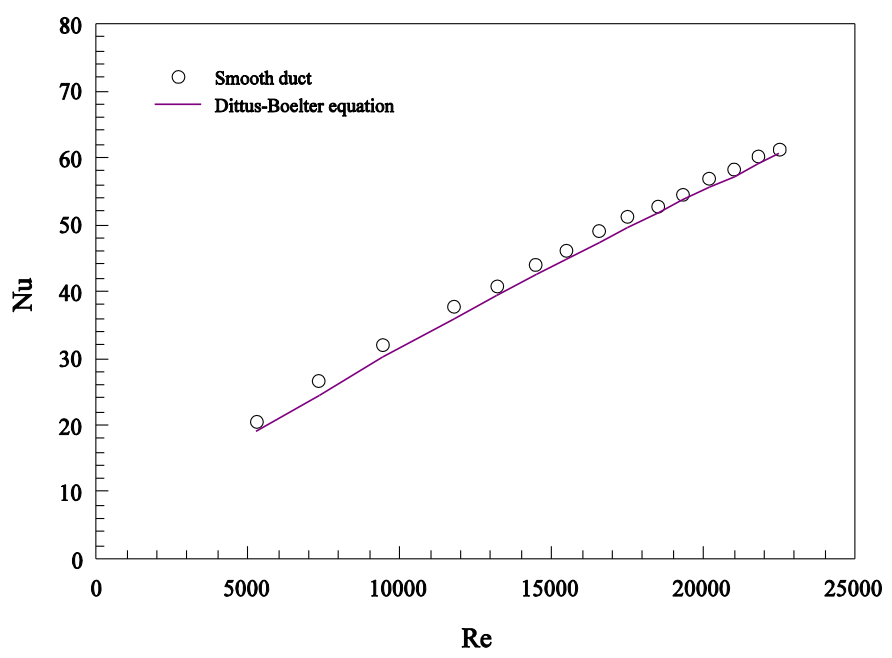

Fig. 3. Confirmatory test of $\mathrm{Nu}$ of smooth duct. 


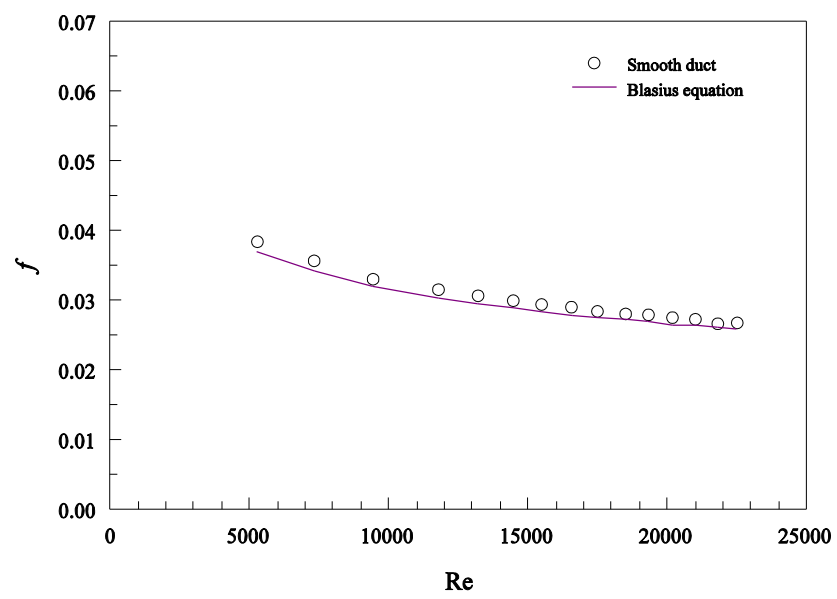

Fig. 4. Confirmatory test of $\mathrm{f}$ of smooth duct.

Manifestly, the results of the present work agree reasonably well within $\pm 7 \%$ for Nu of Dittus-Boelter and $\pm 8.5 \%$ for $f$ of Petukhov correlations, as depicted in Fig. 3 and Fig. 4, respectively.

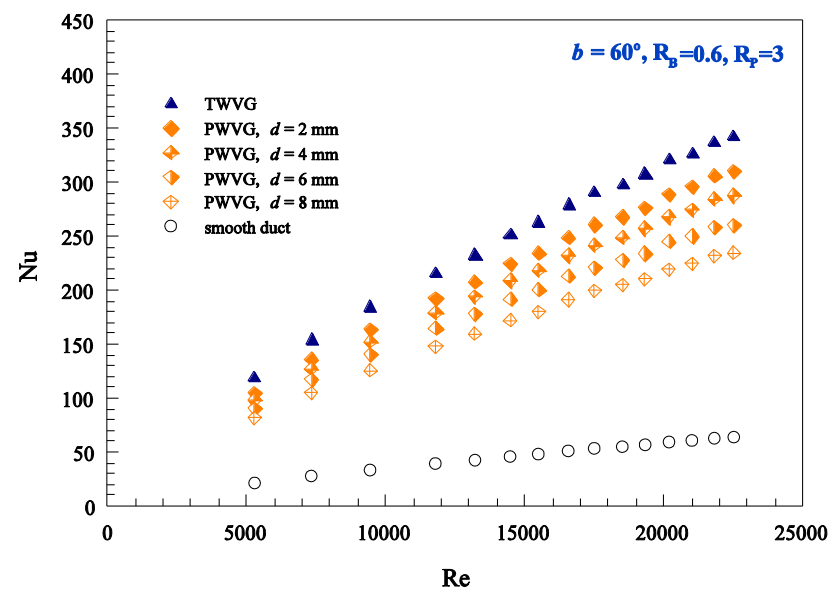

(a)

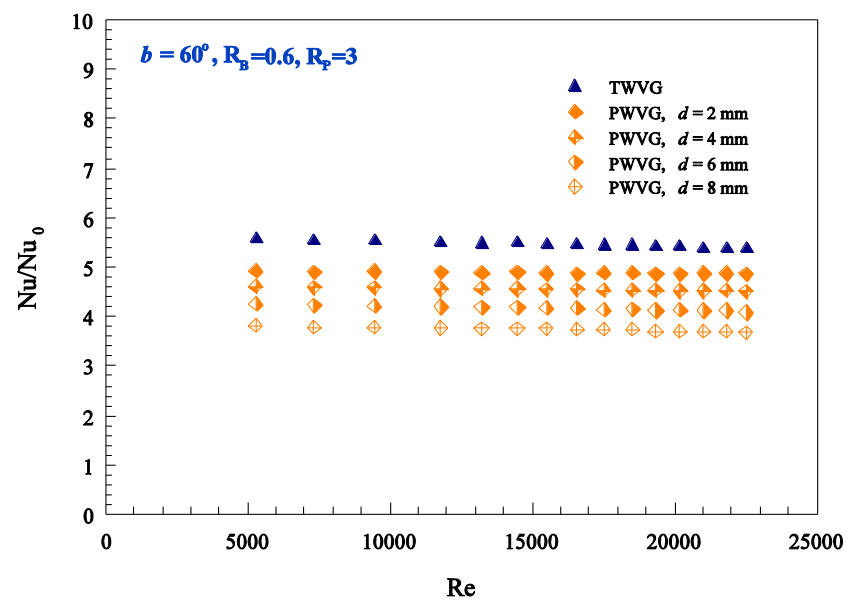

(b)

Fig. 5. Variation of (a) $\mathrm{Nu}$ and (b) $\mathrm{Nu} / \mathrm{Nu}_{0}$ with $\mathrm{Re}$ for PWVG with different $d$ values. 


\subsection{Heat transfer}

Fig. 5(a) and (b) shows the variations of Nusselt number $(\mathrm{Nu})$ and Nusselt number ratio $\left(\mathrm{Nu} / \mathrm{Nu}_{0}\right)$ with Reynolds number (Re) for PWVGs having a fixed value of $\mathrm{R}_{\mathrm{B}}, \mathrm{R}_{\mathrm{P}}$ and $\beta$, while the punched pore diameter of winglet $(d)$ was varied. In Fig. 5(a), Nu of the PWVG was found to be consistently higher than that of the smooth duct alone. The smaller diameter $(d=2 \mathrm{~mm}) \mathrm{PWVG}$ provides higher $\mathrm{Nu}$ than the larger one while the TWVG gives the highest $\mathrm{Nu}$. This indicates that the effect of vortex flow and boundary layer disruption can help to enhance the convection heat transfer and momentum processes.

The variation of $\mathrm{Nu} / \mathrm{Nu}_{0}$ ratio with Re for various hole diameters of winglet is presented in Fig. 5(b). In the figure, it is visible that the $\mathrm{Nu} / \mathrm{Nu}_{0}$ tends to slightly decrease with the rise of Re for all values of $d$. It can be seen that the $\mathrm{Nu} / \mathrm{Nu}_{0}$ increases with the decrease in $d$, attains a maxima at a hole diameter of 2 $\mathrm{mm}$ and thereafter it decreases with increasing $d$. The mean $\mathrm{Nu} / \mathrm{Nu}_{0}$ values are found to be about $4.9,4.6$, 4.2 and 3.7 times above the smooth duct for $d=2 \mathrm{~mm}, 4 \mathrm{~mm}, 6 \mathrm{~mm}$ and $8 \mathrm{~mm}$, respectively. Compared with TWVG, the $\mathrm{Nu} / \mathrm{Nu}_{0}$ values for the TWVG are about $10 \%, 17 \%, 24 \%$ and $31 \%$ higher than those for the PWVG with $d=8 \mathrm{~mm}, 6 \mathrm{~mm}, 4 \mathrm{~mm}$ and $2 \mathrm{~mm}$, respectively.

\subsection{Pressure loss}

The influence of various hole/pore diameters on friction factor $(f)$ and friction factor ratio $\left(f / f_{0}\right)$ against Re is displayed in Fig. 6(a) and (b), respectively. It is observed that the $f$ values from the four $d$ values are in a similar trend and decrease with increasing Re and $d$ values while TWVG gives rise to $f$ much higher than the PWVG as can be seen in Fig. 6a. The higher $f$ in the SAH duct significantly comes from stronger vortex flows apart from the increase in winglet surface area.

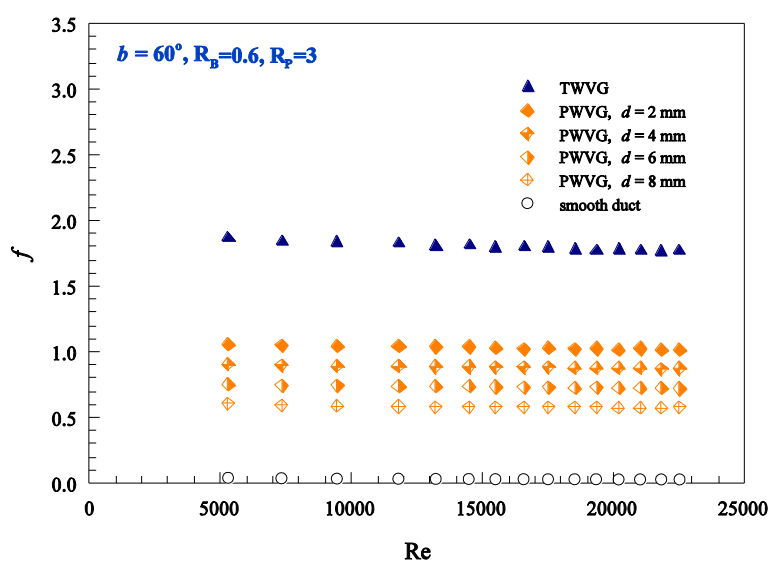

(a)

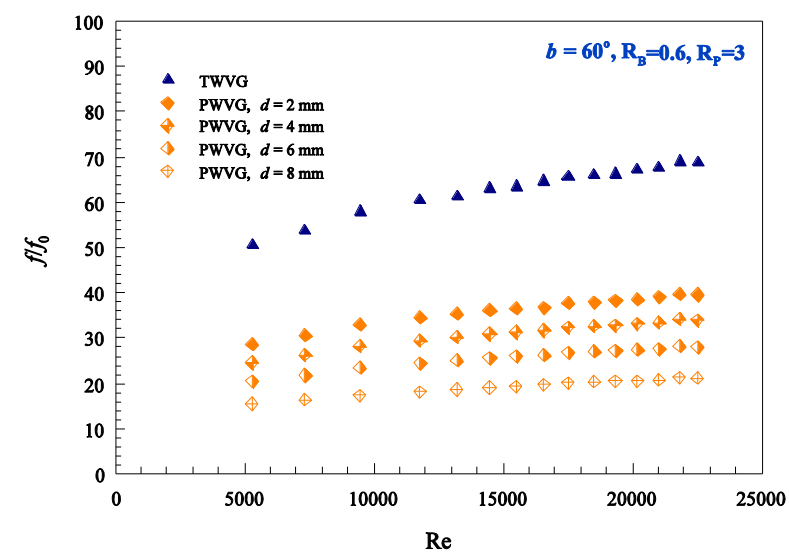

(b)

Fig. 6. Variation of (a) $f$ and (b) $f l f_{0}$ with the Re for PWVG with different $d$ values. 
As seen in Fig. 6(b), the $f / f_{0}$ shows the increasing trend with the increment of Re for all cases. In PWVG cases, the maximum and minimum augmentations in $f$ are observed for $d=8 \mathrm{~mm}$ and $2 \mathrm{~mm}$, respectively. The $f / f_{0}$ values for $d=8 \mathrm{~mm}, 6 \mathrm{~mm}, 4 \mathrm{~mm}$ and $2 \mathrm{~mm}$ are, respectively, ranging from 28.739.7, 24.6-34.1, 20.5-28.1 and 15.5-21.2, depending on Re values. The flf $f_{0}$ values for the TWVG are about $43 \%, 51 \%, 59 \%$ and $69 \%$ higher than those for the PWVG with $d=8 \mathrm{~mm}, 6 \mathrm{~mm}, 4 \mathrm{~mm}$ and $2 \mathrm{~mm}$, respectively. Using a hole on the winglet can reduce the friction loss due to lower flow resistance.

\subsection{Thermal performance}

Fig. 7 shows the variation of thermal enhancement factor (TEF) with Re for different $d$ values. The TEF is determined under the data of the measured $\mathrm{Nu}$ and $f$ values for both the artificial roughness and smooth duct at the same pumping power as defined in Eq. (10). In the figure, TEF tends to decrease with the increase in Re for all. The TEF of the PWVG is considerably higher than that of the TWVG. The TEF values for $d=2 \mathrm{~mm}, 4 \mathrm{~mm}, 6 \mathrm{~mm}$ and $8 \mathrm{~mm}$ are, respectively, about 1.43-1.61, 1.39-1.58, 1.34-1.56 and 1.33-1.53. It is apparent that the PWVG with $d=2 \mathrm{~mm}$ provides the highest TEF of about 1.61. The TEF of PWVGs is found to be higher than the TWVG at about 2-7\%, depend on $d$ values.

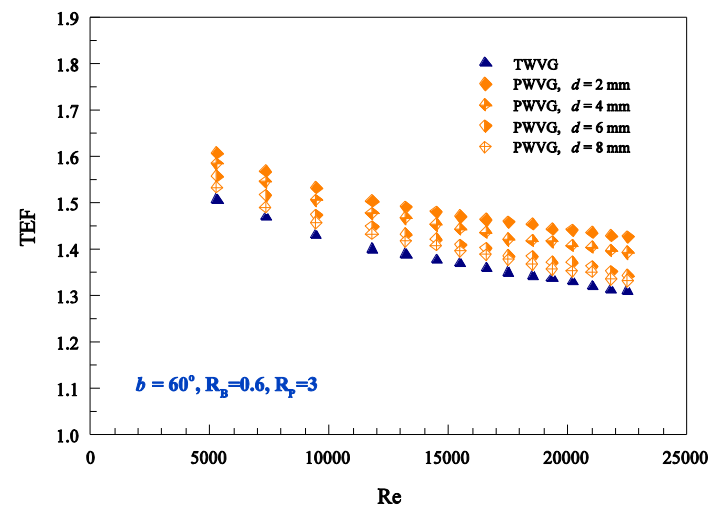

Fig. 7. Effect of TEF on Re.

\section{Conclusions}

The effect of punched pore diameter of the winglet on thermal and flow friction characteristics in a SAH duct has been investigated. For all cases, the Nu increases whereas the $f$ decreases with the increase of Re. The values of $\mathrm{Nu}$ and $f$ are substantially higher as compared to those from the smooth duct. The $\mathrm{Nu}$ and $f$ due to the presence of PRWT increase as the punched pore diameter increases. The PWVG at $d=2$ mm gives the highest $\mathrm{Nu} / \mathrm{Nu}_{0}$ and $f / f_{0}$ of about 4.93 and 39.67 times while the TWVG yields the $\mathrm{Nu} / \mathrm{Nu}_{0}$ and $f l f_{0}$ around 5.46 and 63.12 times, respectively. The highest TEF of 1.61 is achieved by utilizing the winglet with the smallest punched pore diameter $(d=2 \mathrm{~mm})$ due to lower flow resistance. Compared with TWVG, The TEF of PWVGs is found to be higher than the TWVG around 2-7\%, depend on $d$ values. Thus, the use of PWVG is a promising enhancement device for thermal improvement in heating/cooling channels rather than that of the TWVG.

\section{References}

[1] Taslim ME, Li T, Kercher DM. Experimental heat transfer and friction in channels roughened with angled, V-shaped, and discrete ribs on two opposite walls. ASME J. Turbomach, 1996; 118:20-28.

[2] Varun, Saini RP, Singal SK. A review on roughness geometry used in solar air heaters. Sol. Energy, 2007; 81:1340-1350.

[3] Hans VS, Saini RP, Saini JS. Performance of artificially roughened solar air heaters-a review. Renew. Sust. Energ. Rev., 2009; 13: $1854-1869$.

[4] Mochizuki S, Murata A, Fukunaga M. Effects of rib arrangements on pressure drop and heat transfer in a rib-roughened channel with a sharp $180^{\circ}$ turn. ASME J. Turbomach, 1997; 119:610-616. 
[5] Lee DH, Rhee DH, Kim KM, Cho HH, Moon HK. Detailed measurement of heat/mass transfer with continuous and multiple V-shaped ribs in rectangular channel. Energy, 2009; 34:1770-1778.

[6] Tamna S, Skullong S, Thianpong C, Promvonge P. Heat transfer behaviors in a solar air heater channel with multiple V-baffle vortex generators. Sol. Energy, 2014; 110:720-735.

[7] Skullong S, Promvonge P, Thianpong C, Pimsarn M. Thermal performance in solar air heater channel with combined wavygroove and perforated-delta wing vortex generators. Appl. Therm. Eng., 2016; 100:611-620.

[8] Promvonge P, Khanoknaiyakarn C, Kwankaomeng S, Thianpong C. Thermal behavior in solar air heater channel fitted with combined rib and delta-winglet. Int. Commun. Heat Mass Transf., 2011; 38:749-756.

[9] Skullong S, Promvonge P. Experimental investigation on turbulent convection in solar air heater channel fitted with delta winglet vortex generator. Chin. J. Chem. Eng., 2014; 22:1-10.

[10] Incropera FP, Witt PD, Bergman TL, Lavine AS. Fundamentals of Heat and Mass Transfer. John-Wiley \& Sons; 2006. 